\title{
Review
}

\section{Evolutionary change and phylogenetic relationships in light of horizontal gene transfer}

\author{
Luis Bото \\ Departamento de Biodiversidad y Biología Evolutiva, Museo Nacional Ciencias \\ Naturales, CSIC, C/ José Gutierrez Abascal 2, 28006, Madrid, Spain
}

(Fax, 34-915645078; Email, mcnb119@mncn.csic.es)

\begin{abstract}
Horizontal gene transfer has, over the past 25 years, become a part of evolutionary thinking. In the present paper I discuss horizontal gene transfer (HGT) in relation to contingency, natural selection, evolutionary change speed and the Tree-of-Life endeavour, with the aim of contributing to the understanding of the role of HGT in evolutionary processes. In addition, the challenges that HGT imposes on the current view of evolution are emphasized.
\end{abstract}

[Boto L 2015 Evolutionary change and phylogenetic relationships in light of horizontal gene transfer. J. Biosci. 40 465-472] DOI $10.1007 / \mathrm{s} 12038-015-9514-8$

\section{Introduction}

The last 25 years have revealed that different organisms, from bacteria to animals, have acquired and conserved genes derived from other organisms, which has placed horizontal gene transfer, or HGT (the process of incorporation of new genetic material to host genomes, also known as lateral gene transfer, or LTG), in the realm of evolutionary biology.

Known since the early days of molecular biology, and having contributed widely to its development, HGT was initially treated as a curiosity by evolution researchers. However, HGT has played an important role in the evolution of Bacteria and Archaea (Boto 2010; Syvanen 2012), and increasing evidence suggests that it has also modulated evolution in unicellular eukaryotes (Keeling and Palmer 2008; Andersson 2009; Tucker 2013), fungi (Gladieux et al. 2014), plants (Yue et al. 2012; Gao et al. 2014) and animals (Hotopp 2011; Boto 2014; Schoenknecht et al. 2014).

Like other processes and mechanisms revealed in the last years (epigenetic modifications, developmental changes as an internal evolutionary force, etc.), HGT challenges some aspects of the traditional view of evolution emerging from the socalled Modern Synthesis. In this respect, it has been claimed that a new evolutionary synthesis is needed (Dean and Thornton 2007; Carroll 2008; Pigliucci and Mueller 2010).
With the objective of contributing to the positioning of HGT within the current evolutionary framework, I would like to discuss in this paper HGT in regard to three aspects of the current paradigm of evolutionary theory:

1. What is the role of natural selection in the processes leading to the acquisition and maintenance of foreign genes by organisms?

2. How does HGT affect the rate of evolutionary change?

3. How does HGT affect the reconstruction of phylogenetic relationships?

I have deliberately left out of the scope of this paper the discussion concerning the transfer of endosymbiont genes to the host genomes (endosymbiotic gene transfer).

\section{Natural selection and horizontal gene transfer}

The ability of the cells to uptake foreign DNA and the mechanisms allowing this incorporation to bacteria (transformation, conjugation and transduction) has been known since the early years of molecular biology and has fueled the proper development of this discipline, leading to implementation of more applied disciplines such as genetic engineering and biotechnology (Arber 2014). However, despite the

Keywords. Contingency; evolutionary change rate; horizontal gene transfer; natural selection; phylogenetic relationships 
fact that the theoretical evolutionary potential of crossspecies gene transfer was proposed early (Syvanen 1985), it was not until the development of the so-called genomic era, and the realization that HGT is a widespread phenomenon affecting Bacteria, Archaea and eukaryotes, that HGT became a part of evolutionary thinking.

However, to consider HGT as an evolutionary force also requires the knowledge of the role of natural selection in the processes leading to the acquisition and conservation of foreign genetic information.

The uptake of DNA by cells seems to be a contingent event that is derived from the physico-chemical properties of the cell membrane and favoured by the availability of naked DNA or of neighbouring potential DNA donors involved in the processes of conjugation and transduction. However, the stable integration of foreign genetic material in the receptor genome is a complex process that occurs in a dual time frameshift: the cell lifetime and the evolutionary time driving to fixation in cell populations and ultimately in the genetic background of the species.

The journey of a piece of DNA from the donor to the recipient is a long one (figure 1) involving (a) the release from the donor in the form of naked DNA or integrated in bacterial chromosome, plasmids, phages, viruses or other mobile genetic elements, (b) the binding to the cell surface and its sucessful entry in the recipient cell, (c) the integration in the recipient DNA by homologous or illegitimate recombination or its maintenance as a mobile genetic element in the recipient cell, (d) the successful transcription and translation, and finally, (e) the merging in the recipient genetic background only if the traits provided by the gene product are neutral or adaptive (Thomas and Nielsen 2005). In the case of pluricellular eukaryotes with a germ line, a prerequisite to their final merging to the recipient genome is the incorporation of acquired DNA to this germ line.

In addition, the incorporation of new genetic information can disrupt the genome stability that has been acquired over a long evolutionary process. In this sense, it has been proposed that during preorganismic evolution, widespread and promiscuous genetic exchange (Woese 1998) had been dominant. However, the emergence of the current life domains and subsequent organism evolution imposed restrictions on this genetic exchange flux, leading to emergence of a number of different barriers against HGT (Thomas and Nielsen 2005) that overcome the costs imposed by the acquisition of new genetic material (Baltrus 2013).

In the following subsections I will discuss the role of natural selection on the different steps that mark the process of HGT from the donor to recipient genome.

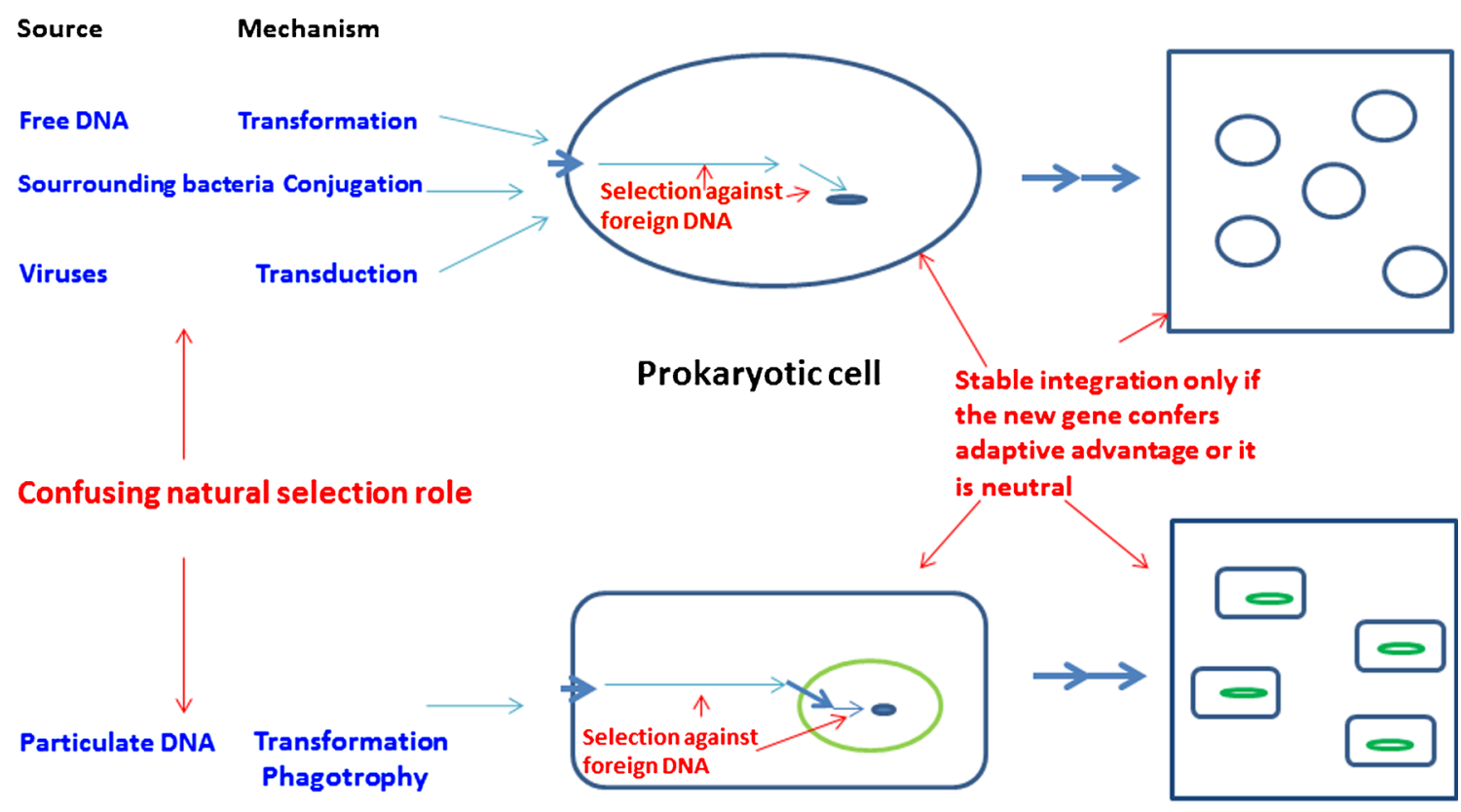

Eukaryotic cell

Population

Figure 1. Schematic representation of the HGT process (see main text for details). Blue arrows show the flux for foreign DNA from the source to their stable integration within the species genetic background. The thicker arrows mark the travel across the cellular surface and nuclear membrane in eukaryotes. Double blue arrows mark the spread of acquired DNA from a single cell to its stable integration within the species genetic background. Red arrows show the role of natural selection in the different process steps. The dense blue ellipse denotes genomes in prokaryotic or eukaryotic cells (for clarity it is not show in populations). The ellipse circled in green represents the eukaryotic cell nuclei. 


\subsection{The first step: Role of the donor}

The prokaryotic cells of Bacteria and Archaea can be transformed by fragments of naked DNA from the sourrounding environment, which are secreted actively by other cells or derived from dead cells. Moreover, they can acquire DNA through classic conjugation and transduction mechanisms or through the aid of transposable elements or recently described gene transfer agents (Thomas and Nielsen 2005; Norman et al. 2009; Popa and Dagan 2011; Lang et al. 2012).

For eukaryotic cells, food particles or free DNA absorbed in mineral surfaces can be sources of foreign DNA (Boto 2014).

In prokaryotic transformation and eukaryotic DNA intake, the raw material for genetic exchange originates from a contingent event: the presence of DNA in the extracellular environment, which originate from other contingent events such as cell death or secretion by other cells.

However, for prokaryotic conjugation, transduction and other HGT mechanisms, vectors (plasmid, phages, viruses, transposable elements and gene transfer agents or GTAs) carrying DNA from other genomes are needed.

It has been recently proposed (Takeuchi et al. 2014 ) that HGT can be a form of rescue from Muller's ratchet (Muller 1964) for bacterial populations, restoring genes that have been deleted or inactivated by mutations. In this sense, natural selection could play a role in the preservation of these vectors and agents along with other cellular components that allow the maintenance of HGT in prokaryotic organisms (see below). Evidence supporting the purifying selection acting on GTA genes has been reported (Lang et al. 2012), suggesting an important role for these elements and underlaying the role of natural selection in its maintenance. However, the possibility remains that these elements may have been recruited or co-opted for HGT secondarily from other cellular funcions (Lang et al. 2012). In the same way, it has been claimed (Redfield 2001; Takeuchi et al. 2014) that conjugation and transduction may be considered to be side effects of the selfish propagation of plasmids and phages.

\subsection{Binding of DNA to recipient cell surface and intake}

All of the mechanisms for HGT discussed above require the modification of the recipient cell surface in order to allow for the intake of DNA into the cell.

In the case of transformation, the existence of competence-induced proteins and other pore-forming components promote the binding of DNA to the cell surface and its ulterior transport to the cell cytoplam. In conjugation and transduction, modifications of the receptor cell surface are induced by donor cells and phages permitting the completion of the genetic exchange process. In the case of HGT that is mediated by GTAs, these elements help the transport across the cell surface barrier (Lang et al. 2012). Finally, in eukaryotes, phagocytic vesicles and other cellular processes facilitate the recipient cell's intake of foreign DNA.

It has been proposed that for transformation and phagocytic processes, the recipient cell plays an active role in the process of DNA intake (Thomas and Nielsen 2005; Moradigaravand and Engelstädter 2013). In the first case, the acquisition of a competence state in response to external conditions involving the synthesis of specific proteins (poreforming components for example), or modification of preexisting ones, prepares the recipient cell for the acquisition of the external DNA. On the other hand, for the phagocytic processes the feeding cellular machinery facilitates the acquisition of exogenous DNA.

However, in conjugation, transduction or gene transfer mediated by transposable elements or GTAs, the active role is played by donors. In the first three cases, the selfish propagation of mobile genetic elements can be sufficient to explain the maintenance of gene transfer vectors (Redfield 2001; Takeuchi et al. 2014). In the case of GTA-mediated gene transfer, an active role of the donor cells has been proposed and evidence of purifying selection acting on GTAs genes has been reported (Lang et al. 2012) (see above).

Taking into account the different mechanisms involved in the uptake of DNA, the role of natural selection in this process is still confusing. In some instances, it is possible that natural selection may have contributed direct or indirectly to the preservation of molecules involved in DNA uptake mechanisms, favouring, for example, the appearance of competence for transformation in several bacterial species (Moradigaravand and Engelstädter 2013); in others this role is unclear.

In some bacterial species such as Haemophilus influenzae or Neisseria gonorrhoeae, the transformation process is highly specific (Mell and Redfield 2014) as these bacteria are transformed by DNA harbouring short sequence motiffs similar to other ones that are widely represented in the bacterial genome, which suggests a role for natural selection in the evolution of this specificity.

\subsection{The travel of foreign DNA to recipient genome}

From previous discussion it is clear that Bacteria, Archaea or eukaryotic cells have preserved a high capacity for DNA uptake. However, before this DNA can be integrated into the recipient genome or estabilished as a mobile genetic element, it needs to travel towards the cell cytoplasm.

The integration of foreign genetic material into a stabilized genome can disrupt gene arrays that have been fitted together over a long evolutionary period. It has therefore been proposed that organisms may have developed barriers to protect themselves from the invasion of foreign genetic elements (Baltrus 2013).

In bacteria, restriction/modification systems (Wilson and Murray 1991), the CRISPRs/Cas system (Horvath and 
Barrangou 2010) or Argonaute proteins (Hur et al. 2014) probably evolved as mechanisms to protect genomes from the invasion of foreign genetic elements.

These systems recognize foreign DNA and degrade it. However occasionally, foreign DNA escapes these cellular defences by unknow mechanisms and finds a way of integrating to the host genome.

On the other hand, DNA ingested by eukaryotic cells is normally degraded and used as a nucleotide source. However, it sometimes continues to travel to the cellular nucleus, where it can be integrated into the host genome.

The integration of foreign DNA to the genome of the recipient cells can occur by homologous or non-homologous (illegitimate) recombination aided by recombinase proteins. In the first case, foreign DNA can result in a new allele for the recipient if it is integrated in a stable form (see below), whereas in the second case, it can give rise to the acquisition of a new gene by the recipient.

All in all, the integration of foreign DNA to the recipient genome seems to be the result of a series of contingent events such as the surmounting of the recipient defence mechanisms or the successful recombination between foreign and recipient DNAs.

\subsection{Stable integration of acquired DNA}

The stable integration of a piece of encoding DNA requires that the acquired DNA be transcribed and expressed in the new cellular context. In this sense, if the acquired DNA is derived from a close phylogenetically related organism, this integration may be easier.

Several recent studies have suggested this to be the case (Andam et al. 2010; Andam and Gogarten 2011; Mell and Redfield 2014). However, HGT between distant organisms (including interdomain transfers) has also been reported, which shows that in these cases barriers to the functional integration of foreign DNA can be overcome.

Genes that are part of a new genome are faced with the problem of its efficient transcription in a different genomic environment. In addition, the codon usage of the recipient cell imposses new fitness costs to ensure the maintenance of the acquired genes. The wrong folding of gene products in the new environment and possible breaking of the cellular protein networks are other fitness costs that acquired genes face on their way to becoming part of the recipient genome (Baltrus 2013).

In this sense, it not surprising that the stable integration of acquired DNA may be a difficult process, which may only be culminated if the new DNA confers an adaptive advantage or is neutral. In the latter case, neutral genes acquired by HGT can experience an amelioration process that equalize their initial base composition with that of the recipient genome (Marri and Golding 2008).
Many of the proposed DNA acquired by eukaryotes show evidence of pseudogenization following the transfer event, especially for that of HGT from bacterial endosymbionts to Arthropods (Nikoh et al. 2008; Campbell et al. 2012; Rice et al. 2013; Brelsfoard et al. 2014), suggesting that purifiying selection is acting against the foreign DNA.

However, empirical studies show contradictory results in regard to the role of purifying selection and fitness costs on the stable integration of HGT acquired genes. While some recent works support the existence of purifying selection and pseudogenization on all the acquired genes (Epstein et al. 2014), other experimental studies reduce the effect of the fitness costs for HGT (Sorek et al. 2007; Knoppel et al. 2014), suggesting that despite the fact that HGT does not confer an immediate advantage, transferred fragments can be maintained and serve as raw materials for the evolution of new functions.

We can conclude that HGT is a rare outcome that emerges from a complex process. In this sense, I would like to conclude this section by including a literal citation from Endymion D Cooper (2014) in a recent comment to an interesting study dealing with HGT between hornworts and ferns (Li et al. 2014):

"What makes this HGT event so interesting is that happened despite being fundamentally improbable. Much like the origin of life itself, HGT-stimulated adaptive radiation of ferns could only have occurred at the intersection of several individually unlikely events and circumstances."

\section{HGT and the pace of evolutionary change}

Gradualism, considered a paradigm of the so-called Modern Synthesis rooted in the Darwinian principle of gradual change, has been pervasive in evolutionary thinking during most of the twentieth century. According to this paradigm, the acquisition of genetic variability, the raw material for natural selection, is only possible through the gradual and slow acquisition of minor variants or point mutations (internal genome reorganizations are considered to be a macromutation shuffling the gradually acquired micro-mutations across the genome).

However, the acquisition of new genes by HGT is a challenging new form of introducing genetic variability that allows for the acquisition of genes that have previously been subjected to natural selection in the donor organism.

The new individual genes can quickly propagate if they offer a clear adaptive advantage to the recipient. This propagation may be facilitated if, instead of a single gene, the transferred material consists of a gene cluster or operon comprising several genes that participate in a particular 
metabolic pathway and that are regulated in a concerted manner (Price et al. 2008).

Figure 2 shows a hypothetical and oversimplified example on how an acquired trait can be quickly spread and consequently contribute to the diversification of the recipient population or species. In this example, a gene or gene cluster $\mathrm{Y}$ affecting the survival of cells of other species (encoding for a toxic compound, an element involved in predation, etc.) is present in a particular species under the control of a weak promoter (p).This gene or gene cluster is transferred to a new species that lacks the gene and whose population has two alleles for a particular gene that provides a different degree of resistance against the product of the new gene ( $R$ and $r$ ). If the acquired gene or genes are under the control of a strong promoter $(\mathrm{P})$ in the recipient, individuals with a weak resistance gene (r) will be eliminated over a few of generations and only the individuals harboring the strong resistance gene (R) will remain. Consequently this species will split into two new and different populations or species depending of the presence or absence of the acquired gene $\mathrm{Y}$.

This example, even if highly hypothetical (only a few genes coding for antibiotic production, for example, have been suggested to be horizontally transferred (Kurosawa et al. 2008)), shows that evolution could rapidly proceed in the presence of HGT.

For other genes that do not have a direct effect on the survival of surrounding species but give a clear selective advantage to the recipient cell (resistance genes, genes involved in the use of a new resource, detoxification genes, etc.), the acquisition of a new functional gene that has been
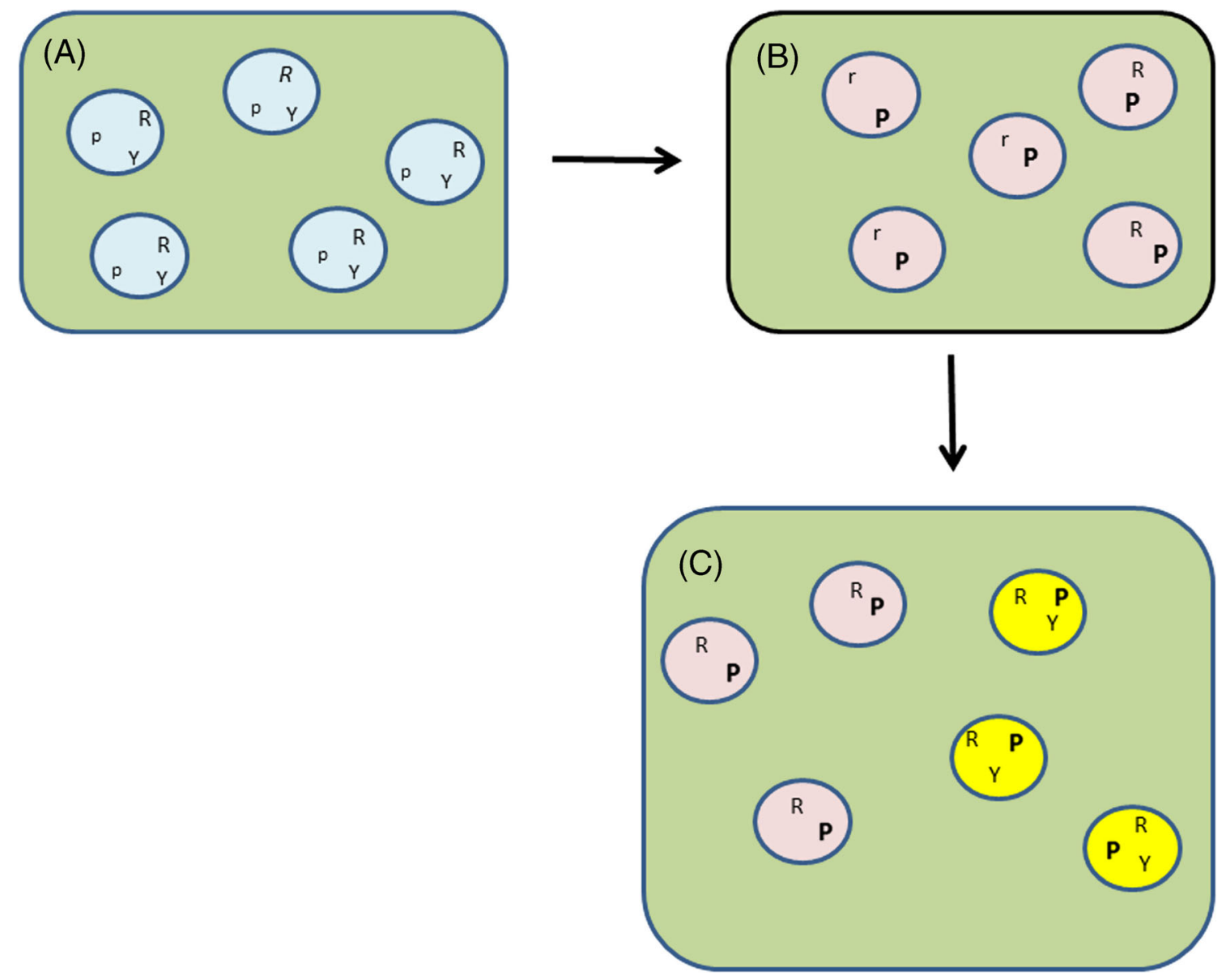

Figure 2. A hypothetical scenario for the rapid spread of acquired genes: Species A transfers Y gene (or gene cluster) that can affect the survival of other species and it is under the control of a weak promoter $\mathrm{p}$ (see main text) to the species B lacking this gene. Species B has two different alleles ( $\mathrm{R}$ and $\mathrm{r}$ ) for a gene conferring resistance against the product of $\mathrm{Y}$ in such a way that the different individuals show different degree of resistance against the acquired gene. If $\mathrm{Y}$ is under the control of a strong promoter $\mathrm{P}$ in species $\mathrm{B}$, individuals with a weak resistance gene $\mathrm{r}$ will be eliminated in a few generations and only individuals with the strong resistance gene $\mathrm{R}$ will survive. Consequently, species B will split into two species: the original species B (pink circles in panel C) without Y gene and a new species (yellow circles in panel C) harbouring the acquired gene. 
previously subjected to natural selection in the donor species will allow the recipient to rapidly colonize new ecological niches speeding up the rate of evolutionary change.

A considerable amount of empirical evidence supports the rapid spread of acquired genes and the fast evolution following HGT, from the spread of antibiotic resistance genes among pathogenic bacteria to the adaptation to plant feeding lifestyles in nematodes and arthropods or land colonization by plants.

However, a gap that needs to be filled in the coming next years is the development of mathematical models of evolution in presence of HGT that will allow for the integration of horizontal gene transfer into the current evolutionary framework.

\section{How does HGT affect the reconstruction of phylogenetic relationships?}

The search for a universal Tree of Life has been a major endeavour for evolutionary biologists since Darwin proposed the Tree of Life metaphor (Darwin 1859). The reconstruction of phylogenetic relationships using morphological characters, and later molecular markers, has proceeded in the framework of a tree-like thinking during most of the twentieth century. However, the discovery of HGT as an evolutionary mechanism in the past 25 years has challenged this framework.

The realization that gene phylogenies are in many cases incongruent with species phylogenies, and that bacterial and archaeal genomes as well as eukaryotic genomes are in many cases a mosaic of genes of different origins, has led some authors to question the Tree of Life metaphor (Doolittle 1999) and favour other ways of depicting the evolutionary history of the life.

This is a fiercely debated topic (McInerney et al. 2008; O'Malley et al. 2010; O'Malley and Koonin 2011) that has lead to the publishing of monographic issues and series in journals such as Biology and Philosophy or Biology Direct.

Several authors maintain the opinion that despite the existence of HGT, a real Tree of Life can be recovered using a reduced number of core genes (Ciccarelli et al. 2006; Gribaldo and Brochier 2009; Matzke et al. 2014). Analysing a great number of gene trees from published bacterial genomes, other authors have suggested the existence of an underlying trend that allows the reconstruction of a subjacent bacterial tree despite rampant horizontal gene transfer (Puigbo et al. 2009, 2010; Koonin et al. 2011).

Some authors have proposed that ancient HGT events may themselves be used as synapomorphies to reconstruct real phylogenetic trees (Huang and Gogarten 2006). In addition, trees based on gene content have also been proposed (Snel et al. 1999) and used to try to recover phylogenetic relationships between bacterial strains and lineages (Nowell et al. 2014).

In this sense, several authors (Lienau and De Salle 2010; Mindell 2013) defend the suitability of the Tree of Life concept adapted to the new evidence that originates not only from the understanding of HGT but also from the realization that other reticulation sources, such as hybridization, contribute to evolution. In this way, the existence of a true tree of cells has been suggested (Franklin-Hall 2010; Valas and Bourne 2010), and that it is superimposed on the reticulation processes that have modulated the evolution of genomes.

On the other side, others authors (Doolittle 1999; Doolittle and Bapteste 2007; Bapteste et al. 2009) oppose fiercely the idea that evolution, at least in the bacterial world, may be depicted as a tree, and defend their position with the argument that a small number of core genes cannot reflect the complex evolutionary history of Bacteria and Archaea. In this sense, several alternative metaphors have been proposed: Ring of Life (Rivera and Lake 2004), Cobweb of Life (Ge et al. 2005), Rhizome of Life (Merhej et al. 2011), Highways of Gene Sharing (Beiko et al. 2005) and others. Currently, the Web of Life (Doolittle 1999), which depicts evolution as a network that reflects the contribution of several evolutionary sources to the genetic background of extant organisms, is the most popular of these.

In addition, an increasing number of bioinformatics tools are being developed to cope with this new scope of evolution such as a network (Dagan 2011; Bapteste et al. 2013; Morrison 2014) that complements the plethora of phylogenetic tools developed in the past to study evolution in the framework of the Tree of Life.

Independent of the fact that some phylogenetic relationships may be recovered in particular cases (i.e., for example, it has been proposed that phylogenetic relationships between eukaryotes can be recovered due to the minor impact of HGT), HGT and other reticulation processes present a philosophycal challenge to the endeavour of describing the evolutionary history of the living world using the Tree of life metaphor, which excludes the participation of processes other than the gradual modification by descent.

In this sense, a redefinition of natural groups and evolutionary units for the microbial world has been proposed (Bapteste and Boucher 2008). Within this scope, evolutionary units may be considered to be composite evolutionary units with different integration levels. In this way, the history of extant biological entities can be split into histories of their different evolutionary units (transferred genes, plasmids, mobile genetic elements, etc.).

\section{Concluding remarks}

Horizontal gene transfer is not just a curiosity; it is time for it to become incorporated into the evolutionary theory as a force modulating the evolution of the living world. Contingency and selection have modulated the acquisition of genetic material by horizontal transfer, which has, in turn, contributed to genomes evolution and allowed the rapid acquisition of evolutionary novelties by organisms. The fast 
spread of this acquired material challenges the gradualistic view of evolution emerging from the so-called Modern Evolutionary Synthesis. Moreover, the incorporation of HGT and other reticulation processes to evolutionary thinking is forcing the development of new methaphors and conceptual frameworks to describe the evolutionary history of extant organisms.

With the aid of an increasing number of bioinformatic tools and the development of mathematical models that account for evolutionary rates in the pressence of HGT, we will be able to understand how HGT has modulated the evolution of life forms.

\section{Acknowledgements}

The author would like to thank Antonio G Valdecasas for the critically reading of the manuscript and Elena Bulmer for the English edition. The author also thanks the two anonymous reviewers and the associate editor for their useful comments. The author has been supported by a grant of Spanish DGI (CGL2013-41375-P).

\section{References}

Andam CP, Williams D and Gogarten JP 2010 Biased gene transfer mimics patterns created through shared ancestry. Proc. Natl. Acad. Sci. USA 107 10679-10684

Andam CP and Gogarten JP 2011 Biased gene transfer in microbial evolution. Nat. Rev. Microbiol. 9 543-555

Andersson JO 2009 Gene Transfer and Diversification of microbial eukaryotes. Annu. Rev. Microbiol. 63 177-193

Arber W 2014 Horizontal gene transfer among bacteria and its role in biological evolution. Life 42 17-224

Baltrus DA 2013 Exploring the costs of horizontal gene transfer. Trends Ecol. Evol. 28 489-495

Bapteste E and Boucher Y 2008 Lateral gene transfer challenges principles of microbial systematics. Trends Microbiol. 16 200-207

Bapteste E, O'Malley MA, Beiko RG, Ereshefsky M, Gogarten JP, Franklin-Hall L, Lapointe FJ, Dupré J, et al. 2009 Prokaryotic evolution and the tree of life are two different things. Biol. Direct 434

Bapteste E, van Iersel L, Janke A, Kelchner S, Kelk S, McInerney JO, Morrison DA, Nakhleh L, et al. 2013 Networks: expanding evolutionary thinking. Trends Genet. 29 439-441

Beiko RG, Harlow TJ and Ragan MA 2005 Highways of gene sharing in prokaryotes. Proc. Natl. Acad. Sci. USA 10214332 14337

Boto L 2010 Horizontal gene transfer in evolution: facts and challenges. Proc. R. Soc. B. 277 819-827

Boto L 2014 Horizontal gene transfer in the acquisition of novel traits by metazoans. Proc. R. Soc. B. 281 2013-2450

Brelsfoard C, Tsiamis G, Falchetto M, Gomulski LM, Telleria E, Alam U, Doudoumis DA, Scolari F, et al. 2014 Presence of extensive Wolbachia symbiont insertions discovered in the genome of its host Glossina morsitans morsitans. PLoS Neglected Trop. Dis. 8 e 2728

Campbell MA, Rokas A and Slot JC 2012 Horizontal transfer and death of a fungal secondary metabolic gene cluster. Genome Biol. Evol. 4 289-293

Carroll SB 2008 Evo-devo and an expanding evolutionary synthesis: A genetic theory of morphological evolution. Cell 134 25-36

Ciccarelli FD, Doerks T, von Mering C, Creevey CJ and Snel Band Bork P 2006 Toward automatic reconstruction of a highly resolved tree of life. Science 311 1283-1287

Cooper ED 2014 Horizontal Gene Transfer: Accidental Inheritance Drives Adaptation. Curr. Biol. 24 R562-R564

Dagan T 2011 Phylogenomic networks. Trends Microbiol. 19 483-491

Darwin C 1859 On the origin of species by means of natural selection or the preservation of favoured races in the struggle for life (London: Murray)

Dean AM and Thornton JW 2007 Mechanistic approaches to the study of evolution: the functional synthesis. Nat. Rev. Genet. 8 675-688

Doolittle WF 1999 Phylogenetic classification and the universal tree. Science 284 2124-2128

Doolittle WF and Bapteste E 2007 Pattern pluralism and the Tree of Life hypothesis. Proc. Natl. Acad. Sci. USA 104 2043-2049

Epstein B, Sadowsky MJ and Tiffin P 2014 Selection on horizontally transferred and duplicated genes in Sinorhizobium (Ensifer), the root-nodule symbionts of Medicago. Genome Biol. Evol. 6 1199-1209

Franklin-Hall LR 2010 Trashing life's tree. Biol. Philos. 25 689-709

Gao C, Ren X, Mason AS, Liu H, Xiao M, Li J and Fu D 2014 Horizontal gene transfer in plants. Funct. Integr. Genom. $1423-$ 29

Ge F, Wang LS and Kim J 2005 The cobweb of life revealed by genome-scale estimates of horizontal gene transfer. PLoS Biol. 3 $1709-1718$

Gladieux P, Ropars J, Badouin H, Branca A, Aguileta G, De Vienne DM, Rodriguez de la Vega RC, Branco S, et al. 2014 Fungal evolutionary genomics provides insight into the mechanisms of adaptive divergence in eukaryotes. Mol. Ecol. 23 753-773

Gribaldo S and Brochier C 2009 Phylogeny of prokaryotes: does it exist and why should we care? Res. Microbiol. 160 513-521

Horvath P and Barrangou R 2010 CRISPR/Cas, the immune system of Bacteria and Archaea. Science 327 167-170

Hotopp JCD 2011 Horizontal gene transfer between bacteria and animals. Trends Genet. 27 157-163

Huang J and Gogarten JP 2006 Ancient horizontal gene transfer can benefit phylogenetic reconstruction. Trends Genet. 22 361-366

Hur JK, Olovnikov I and Aravin AA 2014 Prokaryotic Argonautes defend genomes against invasive DNA. Trends Biochem. Sci. 39 257-259

Keeling PJ and Palmer JD 2008 Horizontal gene transfer in eukaryotic evolution. Nat. Rev. Genet. 9 605-618

Knoppel A, Lind PA, Lustig U, Nasvall J and Andersson DI 2014 Minor fitness costs in an experimental model of horizontal gene transfer in Bacteria. Mol. Biol. Evol. 31 1220-1227

Koonin EV, Puigbo P and Wolf YI 2011 Comparison of phylogenetic trees and search for a central trend in the "Forest of Life". J. Comput. Biol. 18 917-924

Kurosawa K, Ghiviriga I, Sambandan TG, Lessard PA, Barbara JE, Rha C and Sinskey AJ 2008 Rhodostreptomycins, antibiotics 
biosynthesized following horizontal gene transfer from Streptomyces padanus to Rhodococcus fascians. J. Am. Chem. Soc. 130 1126-1127

Lang AS, Zhaxybayeva O and Beatty JT 2012 Gene transfer agents: phage-like elements of genetic exchange. Nat. Rev. Microbiol. 10 472-482

Li FW, Villarreal JC, Kelly S, Rothfels CJ, Melkonian M, Frangedakis E, Ruhsam M, Sigel EM, et al. 2014 Horizontal transfer of an adaptive chimeric photoreceptor from bryophytes to ferns. Proc. Natl. Acad. Sci. USA 111 6672-6677

Lienau EK and De Salle R 2010 Is the microbial tree of life verificationist? Cladistics 26 195-201

Marri PR and Golding GB 2008 Gene amelioration demonstrated: the journey of nascent genes in bacteria. Genome 51 164-168

Matzke NJ, Shih PM and Kerfeld CA 2014 Bayesian analysis of congruence of core genes in Prochlorococcus and Synechococcus and implications on horizontal gene transfer. PLoS One 9 e 85103

McInerney JO, Cotton JA and Pisani D 2008 The prokaryotic tree of life: past, present ... and future? Trends Ecol. Evol. 23 276281

Mell JC and Redfield RJ 2014 Natural Competence and the evolution of DNA uptake specificity. J. Bacteriol. 196 1471-1483

Merhej V, Notredame C, Royer-Carenzi M, Pontarotti P and Raoult D 2011 The rhizome of life: The sympatric Rickettsia felis paradigm demonstrates the random transfer of DNA sequences. Mol. Biol. Evol. 28 3213-3223

Mindell DP 2013 The Tree of Life: Metaphor, model, and heuristic device. Syst. Biol. 62 479-489

Moradigaravand D and Engelstädter J 2013 The evolution of natural competence: Disentangling costs and benefits of sex in bacteria. Am. Nat. 182 E112-E126

Morrison DA 2014 Phylogenetic networks: a review of methods to display evolutionary history. Annu. Res. Rev. Biol. 4 1518-1543

Muller HJ 1964 The relation of recombination to mutational advance. Mutation Res. $12-9$

Nikoh N, Tanaka K, Shibata F, Kondo N, Hizume M, Shimada M and Fukatsu T 2008 Wolbachia genome integrated in an insect chromosome: Evolution and fate of laterally transferred endosymbiont genes. Genome Res. 18 272-280

Norman A, Hansen LH and Sorensen SJ 2009 Conjugative plasmids: vessels of the communal gene pool. Phil. Trans. R. Soc. B. $3642275-2289$

Nowell RW, Green S, Laue BE and Sharp PM 2014 The extent of genome flux and its role in the differentiation of bacterial lineages. Genome Biol. Evol. 6 1514-1529

O'Malley MA, Martin W and Dupre J 2010 The tree of life: introduction to an evolutionary debate. Biol. Philos. 25 441-453

O'Malley MA and Koonin EV 2011 How stands the Tree of Life a century and a half after The Origin? Biol. Direct 632
Pigliucci M and Mueller GB 2010 Elements of an extended evolutionary synthesis; in Evolution the extended synthesis (eds) M Pigliucci and GB Mueller (Cambridge: MIT Press) pp 3-17

Popa O and Dagan T 2011 Trends and barriers to lateral gene transfer in prokaryotes. Curr. Opin. Microbiol. 14 615-623

Price MN, Dehal PS and Arkin AP 2008 Horizontal gene transfer and the evolution of transcriptional regulation in Escherichia coli. Genome Biol. 9 R4

Puigbo P, Wolf YI and Koonin EV 2009 Search for a 'Tree of Life' in the thicket of the phylogenetic forest. J. Biol. 859

Puigbo P, Wolf YI and Koonin EV 2010 The Tree and Net Components of Prokaryote Evolution Genome. Biol. Evol. 2 745-756

Redfield RJ 2001 Do bacteria have sex? Nat. Rev. Genet. 2634 639

Rice DW, Alverson AJ, Richardson AO, Young GJ, SanchezPuerta MV, Munzinger J, Barry K, Boore JL, et al. 2013 Horizontal transfer of entire genomes via mitochondrial fusion in the angiosperm Amborella. Science 342 1468-1473

Rivera MC and Lake JA 2004 The ring of life provides evidence for a genome fusion origin of eukaryotes. Nature 431 152-155

Schoenknecht G, Weber APM and Lercher MJ 2014 Horizontal gene acquisitions by eukaryotes as drivers of adaptive evolution. Bioessays 36 9-20

Snel B, Bork P and Huynen MA 1999 Genome phylogeny based on gene content. Nat. Genet. 21 108-110

Sorek R, Zhu Y, Creevey CJ, Francino MP, Bork P and Rubin EM 2007 Genome-wide experimental determination of barriers to horizontal gene transfer. Science 318 1449-1452

Syvanen M 1985 Cross-species gene-transfer. Implications for a new theory of evolution. J. Theor. Biol. 112 333-343

Syvanen M 2012 Evolutionary Implications of Horizontal Gene Transfer. Annu. Rev. Genet. 46 341-358

Takeuchi N, Kaneko K and Koonin EV 2014 Horizontal Gene transfer can rescue prokaryotes from Muller's ratchet: Benefit of DNA from dead cells and population subdivision. G3-Genes Genomes Genetics 4 325-339

Thomas CM and Nielsen KM 2005 Mechanisms of, and barriers to, horizontal gene transfer between bacteria. Nat. Rev. Microbiol. 3 711-721

Tucker RP 2013 Horizontal gene transfer in Choanoflagellates. J. Exp. Zool. B-Mol. Dev. Evol. 320 1-9

Valas RE and Bourne PE 2010 Save the tree of life or get lost in the woods. Biol. Direct 544

Wilson GG and Murray NE 1991 Restriction and modification systems. Annu. Rev. Genet. 25 585-627

Woese C 1998 The universal ancestor. Proc. Natl. Acad. Sci. USA 95 6854-6859

Yue J, Hu X, Sun H, Yang Y and Huang J 2012 Widespread impact of horizontal gene transfer on plant colonization of land. Nature Com. 31152

MS received 12 December 2014; accepted 23 February 2015

Corresponding editor: STUART A NEWMAN 